\title{
The Effects of Leadership Behaviors on Organization Agility: A Quantitative Study of 126 U.S.-Based Business Units
}

\author{
Gretchen Gagel $^{1, *}$ \\ ${ }^{1}$ Australia National University; University of Denver, Canberra, ACT 2600, Australia \\ *Correspondence: Australia National University; University of Denver, Canberra, ACT 2600, Australia. Tel: \\ 61-409-133-803
}

Received: May 10, 2020

Accepted: September 22, 2020

Online Published: October 13, 2020

doi:10.5430/mos.v7n1p1

URL: https://doi.org/10.5430/mos.v7n1p1

\begin{abstract}
Researchers have theorized that the behaviors of organization leaders impact organization agility, which is defined as the ability of an organization to swiftly and successfully change in order to achieve long-term success. The purpose of this study was to determine if leadership behaviors as measured by the MLQ-5X predict organization agility as measured by the Agility Survey (short-form). The research sample included 126 U.S.-based business units within 47 organizations with greater than 1,000 employees.

The leadership behaviors found to predict higher levels of organization agility included: (a) exploratory leadership behaviors that support discovering new ways to solve problems and conduct business, (b) latitude leadership behaviors that provide employees with a high degree of freedom and responsibility in achieving work results and resolving issues, (c) visionary leadership behaviors that create a clear organization purpose and mission and define the "why" of the organization's existence, and (d) reflective leadership behaviors that cause leaders to challenge their own assumptions and create mechanisms for the organization to do so as well. The leadership behaviors related to power and structure predicted lower levels of organization agility.
\end{abstract}

Keywords: agile, agile organization, organizational agility, leadership, transformational leadership, agile leader

\section{Introduction}

The ability of organizations to stay relevant by responding swiftly to market changes to achieve sustained profitability is a critical issue in today's global economy (Holbeche, 2015; O'Reilly \& Tushman, 2016; Worley, Williams, \& Lawler, 2014). These external forces in the business environment include rapidly changing technology, intensified competition, changing customer demands, changes in government regulations, and the rise of developing markets (Belasco, 1990; Brown \& Eisenhardt, 1995; Burke \& Litwin, 1992; Worley et al., 2014). Leadership as an action involves the mobilization of resources to achieve the desired results of an organization (Burns, 1978). Those exercising leadership realize that shifts in the external environment will occur and that an organization must change to react to these shifts and achieve long-term success (Crocitto \& Youssef, 2003; Meyer, 2015).

Agility has been researched at the individual, leader, business unit, and organizational levels, within specific industries such as manufacturing and software development, and within specific areas of expertise such as supply chain management (Crocitto \& Youssef, 2003; Holbeche, 2015; Sharifi \& Zhang, 1999; Sull, 2009). The focus of this research is organization agility at the business unit level.

\subsection{Conceptual Framework of Organization Agility}

The conceptual framework developed by Worley et al. (2014) was selected for this study because this conceptual framework was frequently referenced in the literature reviewed and is grounded in qualitative research. In addition to developing this conceptual framework of organization agility, Worley et al. (22014) also developed an instrument for measuring organization agility that has been utilized by academic researchers.

Worley et al. (2014) described four constructs of agile organizations in the conceptual framework: 
1. Agile strategizing. This construct describes actions related to developing organization strategies; managing, monitoring, and measuring the effectiveness of these strategies; developing an aspirational purpose; and focusing on the breadth, aggressiveness, and differentiation of the strategic positioning of the organization.

2. Agile perceiving. This construct describes actions related to sensing the environment and sharing that information with decision-makers who then interpret the signals of the environment.

3. Agile testing. This construct describes actions related to setting up the test, running the test, and learning from the test of new strategies.

4. Agile implementing. This construct describes actions related to effectively implementing new strategies.

\subsection{Conceptual Framework of Transformational Leadership}

Transformational leadership theory was chosen for this study because many of the behaviors and attributes reflected in the conceptual framework of transformational leadership are reflected in the conceptual frameworks of organization agility (Bass \& Riggio, 2006; Holbeche, 2015; Meyer, 2015; Worley et al., 2014). The Bass and Riggio (2006) conceptual framework of a transformational leadership is comprised of four elements.

1. Idealized Influence (II). This construct has two elements: (a) the attributes the followers attribute to the leader such as persistence, determination, and outstanding capabilities (Idealized Influence (attributed)); and (b) the behaviors of the leader, which are described as those of a role model with high moral and ethical standards (Idealized Influence (behavior)) (Bass \& Riggio, 2006). The transformational leader is focused upon the need for a common mission and is admired, trusted, and respected by his or her followers (Bass \& Riggio, 2006).

2. Inspirational Motivation (IM). The construct describes the behaviors of a transformational leader that motivate and inspire those around them, including a focus on providing meaning and challenge in the work setting (Bass \& Riggio, 2006). This element of transformation leadership involves providing a vision of the desired future state, clearly communicating common goals and inspiring followers through team spirit, enthusiasm, and optimism (Bass \& Riggio, 2006).

3. Intellectual Stimulation (IS). This construct describes a leader's ability to cause followers to question assumptions, look at problems in new ways, and display a high level of creativity (Bass \& Riggio, 2006). The leader does not publicly criticize mistakes, but instead encourages new ideas, new approaches, and new ways of thinking (Bass \& Riggio, 2006).

4. Individualized Consideration (IC). This construct describes how transformational leaders pay attention to the needs of each individual, working to develop the individual to his or her full potential in a supportive climate (Bass \& Riggio, 2006). This involves "management by walking around" (Bass \& Riggio, 2006, p. 7), strong two-way communication, and treating the follower as a whole person, not just an employee (Bass \& Riggio, 2006). Transformational leaders are adept at delegating tasks, coaching, and teaching their followers (Bass \& Riggio, 2006).

\subsection{Research Question}

The purpose of this research was to determine the degree to which the leadership behaviors and attributes of U.S.-based business unit leaders predict the organization agility of that business unit, thereby advancing the theory of organization agility at the business unit level with generalizability to the organization level.

The following research question was established for this research study:

RQ: What are the perceived behaviors and attributes of business unit leaders, as reported by the direct reports of business unit leaders and measured by the Multifaceted Leadership Questionnaire (MLQ - 5X), that predict higher scores on organization agility for that business unit, as measured by the Agility Survey (short-form).

The following hypothesis was made:

$\mathrm{H} 1$ : The presence of certain leadership behaviors and attributes for a business unit leader, as measured by the MLQ-5X, predicts a higher score on organization agility for that business unit, as measured by the Agility Survey (short-form).

The null hypothesis is: 
H0: The presence of certain leadership behaviors and attributes of a business unit leader, as measured by the MLQ-5X, have no relation to the level of organization agility of that business unit, as measured by the Agility Survey (short-form).

Independent Variables

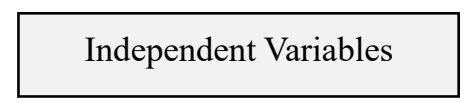

\section{Dependent Variable}

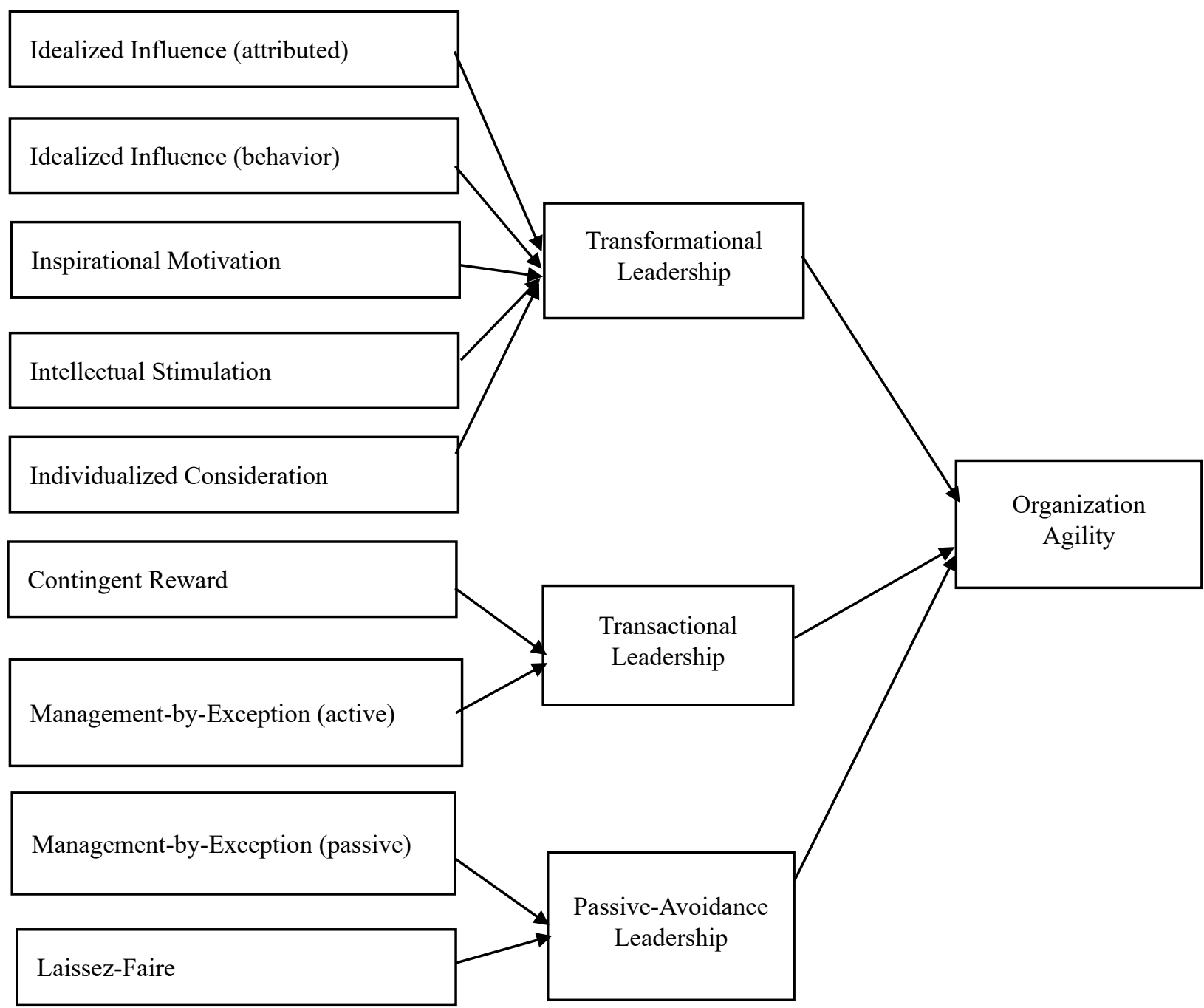

Figure 1. Research Design Representing Nine Elements and Three Leadership Constructs as Independent Variables

The research model, illustrated in Figure 1, contained two sets of independent variables: 1) the nine elements of leadership behaviors assumed to be reflected in the MLQ-5X data: Idealized Influence (attributed; four items), Idealized Influence (behavior; four items), Inspirational Motivation (four items), Intellectual Stimulation (four items), Individualized Consideration (four items), Contingent Reward (four items), Management-by-Exception (active; four items), Management-by-Exception (passive; four items), and Laissez-Faire Leadership (four items); and 2) the three leadership constructs assumed to be reflected in the MLQ-5X: (a) Transformational Leadership, comprised of Idealized Influence (attributed), Idealized Influence (behavior), Inspirational Motivation, Intellectual Stimulation, and Individualized Consideration; (b) Transactional Leadership, comprised of Contingent Reward and Management-by-Exception (active); and (c) Passive-Avoidance Leadership, comprised of Management-by-Exception (passive) and Laissez-Faire Leadership. The research study included one dependent 
variable, the organization agility of the business unit, as measured by the Agility Survey (short-form) Total Agility Score (Bass \& Avolio, 1994; Bass \& Riggio, 2006; Worley et al., 2014), The research design followed a quantitative, nonexperimental design utilizing Likert scale survey instruments for the measurement of the independent and dependent variables with an assumption of normally distributed data (Tabachnick \& Fidell, 2007).

\section{Methods}

\subsection{Population and Sample}

The sampling methods of random selection and convenience sampling were utilized to solicit the participation of U.S.-based business units and business unit leaders within organizations with greater than 1,000 employees (Tabachnick \& Fidell, 2007). Prior to initiating the research study, a sample size of 119 business units was selected to achieve a margin of error of .03, with an alpha of .05 and $t=1.96$ (Bartlett, Kotrlik, \& Higgins, 2001). G*Power statistical software was also utilized to determine that for a desired power of .80, effect size 22 of .15 (medium), and nine predicting variables, the sample size necessary was 114 .

\subsection{Instruments and Measurement}

The MLQ-5X leadership survey was chosen for this study because of the alignment between several of the items of the survey and the described behaviors and attributes of the leaders of highly agile organizations ((Brown \& Eisenhardt, 1998; Holbeche, 2015; Meyer, 2015; Worley et al., 2014). Research utilizing the MLQ-5X has achieved high levels of construct validity, although there is recognition that several researchers have been unable to replicate the nine-element model of the MLQ-5X (Bass \& Riggio, 2006). The review of literature included both studies confirming score validity for the nine-element construct model for the MLQ-5X and studies that did not conduct confirmatory or exploratory factor analysis to assess score validity for the nine-element construct model for the MLQ-5X (Bass \& Riggio, 2006; Flanigan, Bishop, Brachle, \& Winn, 2017; Frieder, Hemsworth, Muterera, \& Baregheh, 2013; Wang, \& Oh, 2018).

The Agility Survey (short-form) was chosen as the measurement instrument for organization agility. Data were collected from November 1, 2017, to May 17, 2018, from 126 U.S.-based business units within 47 organizations with greater than 1,000 employees. Random sampling accounted for $65.96 \%$ of the participating companies and $70.63 \%$ of the business unit sample. The remaining business unit sample was secured using convenience sampling (see Table 1). Data for the MLQ-5X leadership survey were collected from 751 individuals who were asked to respond regarding their direct business unit leader for the 126 business units. Data for the Agility Survey (short-form) were collected from 1,479 individuals within each of the 126 business unit either by soliciting all employees in the business unit or a random sample.

Table 1. Research Study Sampling Method Statistics

\begin{tabular}{lcccc}
\hline & $n$ & $\%$ & $n$ & $\%$ \\
Sampling Method & Organizations & Organizations & Business units & $\begin{array}{c}\% \\
\text { Business units }\end{array}$ \\
\hline Random & 31 & 65.96 & 89 & 70.63 \\
Convenience & 16 & 34.04 & 37 & 29.37 \\
Total & 47 & 100.00 & 126 & 100.00 \\
\hline
\end{tabular}

A comparison of the Total Agility Score for these two categories revealed that the Total Agility Score for the organizations in the random sample $(M=3.97, S D=.39)$ was not significantly different from the Total Agility Score for the organizations in the convenience sample $(M=3.82, S D=.50) ; t=1.80, d f=124, p=.074$.

\section{Findings}

\subsection{Sample Demographic Profile}

Demographic information for each participating organization and business unit, is displayed in Table 2, including organization type ((a) for-profit (both privately held and publicly traded) and (b) not-for-profit/government agency); founding year ((a) those founded in 1960 or before, and (b) those founded in 1961 or after); and approximate number of employees ((a) 1,000 to 6,000 employees and (b) over 6,000 employees). The gender of each business unit leader 
was obtained, as well as whether the business unit was comprised of fewer than or greater than 100 employees. A diverse range of industries was represented in the data sample and is shown in Table 3.

Table 2. Study Sample Demographic Profile

\begin{tabular}{|c|c|c|c|c|}
\hline Sample Demographic & $\begin{array}{c}n \\
\text { Organizations } \\
\end{array}$ & $\begin{array}{c}\% \\
\text { Organizations } \\
\end{array}$ & $\begin{array}{c}n \\
\text { Business units }\end{array}$ & $\begin{array}{c}\% \\
\text { Business units }\end{array}$ \\
\hline \multicolumn{5}{|l|}{ Type of Organization: } \\
\hline For Profit & 41 & 87.23 & 101 & 80.16 \\
\hline Not-for profit/Gov. Agency & 6 & 12.87 & 25 & 19.84 \\
\hline Total & 47 & 100.00 & 126 & 100.00 \\
\hline \multicolumn{5}{|l|}{ Number of Employees: } \\
\hline 1,000 to 6,000 & 22 & 46.81 & 62 & 49.21 \\
\hline Over 6,000 & 25 & 53.19 & 64 & 50.79 \\
\hline Total & 47 & 100.00 & 126 & 100.00 \\
\hline \multicolumn{5}{|l|}{ Year Founded: } \\
\hline 1960 and before & 28 & 59.57 & 58 & 46.03 \\
\hline 1961 and after & 19 & 40.43 & 68 & 53.97 \\
\hline Total & 47 & 100.00 & 126 & 100.00 \\
\hline \multicolumn{5}{|l|}{ Business Unit Leader Gender: } \\
\hline Male & NA & NA & 86 & 68.25 \\
\hline Female & NA & NA & 40 & 31.75 \\
\hline Total & & & 126 & 100.00 \\
\hline \multicolumn{5}{|l|}{$\begin{array}{l}\text { Number of Employees in the } \\
\text { Business Unit: }\end{array}$} \\
\hline Less than 100 & NA & NA & 57 & 45.24 \\
\hline 100 or more & NA & NA & 69 & 54.76 \\
\hline Total & & & 126 & 100.00 \\
\hline
\end{tabular}

Table 3. Industries Represented in the Study Sample

\begin{tabular}{lcccc}
\hline \multicolumn{1}{c}{ Industries Represented } & $n$ & $\%$ & $n$ & $\begin{array}{c}\% \\
\text { Business units }\end{array}$ \\
\hline Construction & Organizations & Organizations & Business units & 23.02 \\
Energy & 12 & 25.53 & 29 & 9.52 \\
Government Agency & 7 & 14.89 & 12 & 7.94 \\
Healthcare & 5 & 10.64 & 9 & 7.14 \\
University & 3 & 6.38 & 5 & 3.97 \\
Manufacturing & 3 & 6.38 & 8 & 6.35 \\
Engineering & 3 & 6.38 & 9 & 7.14 \\
Insurance & 3 & 6.38 & 9 & 7.14 \\
Hospitality/Food Retail & 2 & 4.26 & 15 & 11.9 \\
Mining & 1 & 2.13 & 5 & 3.97 \\
Food Distribution & 1 & 2.13 & 1 & .79 \\
Employment Services & 1 & 2.13 & 5 & 3.97 \\
Transportation & 1 & 2.13 & 2 & 1.59 \\
Real Estate & 1 & 2.13 & 1 & .79 \\
Food Retail & 1 & 2.13 & 1 & .79 \\
Technology & 1 & 2.13 & 4 & 3.17 \\
Human Services & 1 & 2.13 & 1 & .79 \\
Total & 1 & 2.13 & 126 & 100.00 \\
\hline
\end{tabular}




\subsection{Reliability and Validity}

The means, standard deviations and skewness are reported in Table 4. Cronbach's alpha was calculated to determine the degree of fit for each of the nine elements of the MLQ-5X leadership survey, the three leadership constructs, and the Total Agility Score (see Table 5). These results indicate a low level of reliability for all nine elements except for Intellectual Stimulation (Cronbach's alpha $=.78$ ) and Management-by-Exception (Cronbach's alpha = .78) (Morgan et al., 2013). These results indicated a moderate level of reliability for the Transformational Leadership style, an adequate reliability for the Passive-Avoidance Leadership styles, and low levels of reliability for the Transactional Leadership style for the MLQ-5X original factors (Morgan et al., 2013). Cronbach's alpha was also calculated for the data for the Total Agility Score (alpha $=.96$ ), which indicates a high level of reliability (Morgan et al., 2013).

Table 4. Means, Standard Deviations, and Skewness for Study Variables

\begin{tabular}{lccc}
\hline Variable & $M$ & $S D$ & \multicolumn{2}{c}{ Skewness } \\
\hline Total Agility Score & 3.91 & .43 & -.64 \\
Idealized Influence (attributed) (IA) & 3.30 & .38 & -.28 \\
Idealized Influence (behavior) (IB) & 2.62 & .27 & -30 \\
Inspirational motivation (IM) & 3.49 & .33 & -.59 \\
Intellectual stimulation (IS) & 3.79 & .54 & .12 \\
Individualized consideration (IC) & 3.05 & .26 & -.43 \\
Contingent Reward (CR) & 3.45 & .36 & -.07 \\
Management-by-Exception (active) (MBEA) & 3.02 & .29 & -.42 \\
Management-by-Exception (passive) (MBEP) & 3.66 & .57 & -.39 \\
Laissez-Faire Leadership (LF) & 3.50 & .31 & -.74 \\
Transformational Leadership & 3.25 & .25 & -.21 \\
Transactional Leadership & 3.24 & .29 & -.45 \\
Passive-Avoidance Leadership & 3.59 & .40 & \\
\hline
\end{tabular}

Table 5. Cronbach's Alpha for All Dependent and Independent Variables

\begin{tabular}{lcc}
\hline \multicolumn{1}{c}{ Independent and Dependent Variables } & No. of Items & Reported Cronbach's Alpha \\
\hline Idealized Influence (attributed) & 4 & .12 \\
Idealized Influence (behavior) (IB) & 4 & -.19 \\
Inspirational Motivation (IM) & 4 & .21 \\
Intellectual Stimulation (IS) & 4 & .78 \\
Individualized Consideration & 4 & .02 \\
Contingent Reward (CR) & 4 & .24 \\
Management-by-Exception (active) (MBEA) & 4 & -.16 \\
Management-by-Exception (passive) (MBEP) & 4 & .78 \\
Laissez-Faire Leadership (LF) & 4 & .31 \\
Transformational Leadership & 20 & .69 \\
Transactional Leadership & 8 & .37 \\
Passive-Avoidance Leadership & 8 & .75 \\
Total Agility Score & 19 & .96 \\
\hline
\end{tabular}

Confirmatory factor analysis was selected to determine the score validity of the MLQ-5X data. Data analysis commenced by checking the assumptions two primary assumptions: (a) there would be a relationship between the items, and (b) a sufficient sample size would be present to generate reliable factor analysis results (Morgan et al., 2013). The number of variables should not exceed the number of participants, and in this instance, the number of items, 36, did not exceed the number of participants, 751 (Morgan et al., 2013).

The results of the confirmatory factor analysis of the MLQ-5X data indicate that the anticipated framework of nine elements was not present for this data set, as the chi-square reported was 5.321, which was greater than the necessary result of 5.0 (Brown, 2015). The Root Mean Square Error of Approximation (RMSEA) of .078 also indicated only a moderately good fit for this model (Brown, 2015). In addition, confirmatory factor analysis was performed to explore the goodness of fit of the data for the model of the three expected leadership constructs - transformational, 
transactional, and passive-avoidance - to determine if these constructs as described earlier existed for this data set. The reported chi-square of 6.40 indicates a poor model fit, as does the RMSEA of .129, which should be less than .05 to indicate a good model fit and between .05 and .10 to indicate a moderate model fit. (Brown, 2015). In summary, the confirmatory factor analysis performed did not confirm the validity of either the nine-element model or the three-leadership-construct model for the MLQ-5X for this data set.

\subsection{Alternative Research Model}

Prior research has indicated that the 36 items of the MLQ-5X factor into various models for different data sets (Bass \& Riggio, 2006). Given the results reported above a decision was made to explore an alternative model of leadership behaviors and attributes present for this data set.

\subsection{Validity}

Exploratory factor analysis of principal factor analysis with promax rotation was conducted to assess the underlying structure of the 36 items of the MLQ-5X. After rotation, the first factor accounted for $31.6 \%$ of the variance, Factor 2 accounted for $5.1 \%$ of the variance, Factor 3 for $4.3 \%$, Factor 4 for $2.7 \%$, and Factor 5 for $1.8 \%$, for a total explained variance of $45.6 \%$. Table 6 displays the items and factor loading for the rotated factors. The reported KMO was .91, indicating sampling adequacy, $d f=630$ and alpha $=.001$.

Table 6. Exploratory Factor Loadings for the MLQ-5X Items

\begin{tabular}{|c|c|c|c|c|c|}
\hline \multirow{2}{*}{ Item } & \multicolumn{5}{|c|}{ Factor Loadings } \\
\hline & 1 & 2 & 3 & 4 & 5 \\
\hline MBEP4 & .831 & & & & \\
\hline MBEP3 & .787 & & & & \\
\hline MBEP2 & .777 & & & & \\
\hline IS3 & .638 & & & & \\
\hline IS4 & .445 & & & & \\
\hline IM3 & .345 & & & & \\
\hline IM1 & & .819 & & & \\
\hline MBEA2 & & .790 & & & \\
\hline LF2 & & .728 & & & \\
\hline IS1 & & .722 & & & \\
\hline IS2 & & .598 & & & \\
\hline LF4 & & .551 & & & \\
\hline IB2 & & .471 & & & \\
\hline MBEA1 & & .407 & & & \\
\hline IM4 & & & -.838 & & \\
\hline IC4 & & & -.792 & & \\
\hline IB1 & & & -.688 & & \\
\hline IA3 & & & -.630 & & \\
\hline MBEA4 & & & -.623 & & \\
\hline IC3 & & & & .636 & \\
\hline CR3 & & & & .575 & \\
\hline IC2 & & & & .552 & \\
\hline IB4 & & & & .493 & \\
\hline MBEP1 & & & & .487 & \\
\hline CR1 & & & & .463 & \\
\hline MBEA3 & & & & & .652 \\
\hline CR4 & & & & & .628 \\
\hline IA 4 & & & & & .585 \\
\hline CR & & & & & .584 \\
\hline Percentage of Variance & 31.6 & 5.1 & 4.3 & 2.7 & 1.8 \\
\hline
\end{tabular}

Note. Loadings $<.3$ are omitted. 
The first factor gathered around reported leadership behaviors and attributes that reflect an "exploratory" leader, with items such as "gets me to look at problems from many different angles" and "suggests new ways of looking at how to complete assignments," and a "hands-off" leader, with items such as "waits for things to go wrong before taking action," "shows that he/she is a firm believer in 'if it ain't broke, don't fix it," and "demonstrates that problems must be chronic before taking action." Factor 1 was labeled Exploratory/Latitude Leadership Behaviors

The second factor gathered around reported leadership behaviors and attributes that reflect (a) a "visionary" leader, with items such as "specifies the importance of having a strong sense of purpose," and "talks optimistically about the future"; (b) a "reflective" leader, with items such as "re-examines critical assumptions to question whether they are appropriate," "seeks differing perspectives when solving problems," "focuses attention on irregularities, exceptions, and deviations from standards," and "concentrates his/her full attention when dealing with mistakes, complaints and failures"; and also (c) a "hands off" leader, with items such as "is absent when needed" and "delays responding to urgent questions." Factor 2 was labeled Visionary/Reflective/Latitude Leadership Behaviors.

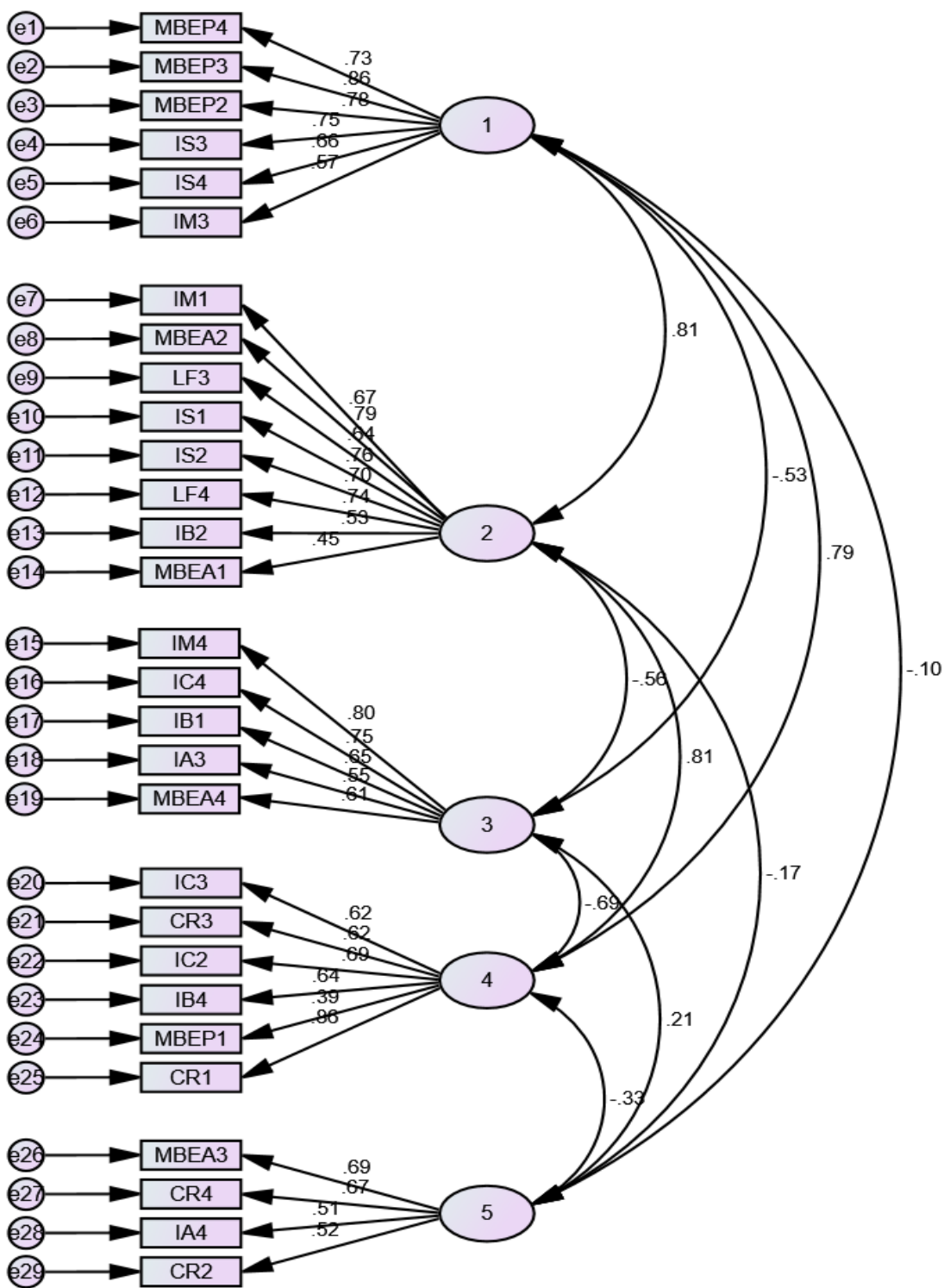

Figure 2. Confirmatory Factor Analysis for the MLQ-5X Alternative Five-Factor Model 
The third factor gathered around reported leadership behaviors and attributes that reflect (a) "value-based" leadership, with items such as "talks about their most important values and beliefs" and "acts in ways that build my respect"; and also (b) an "achievement" leader, with items such as "expresses confidence that goals will be achieved," "directs my attention towards failures to meet standards," and "helps me develop my strengths." Factor 3 was labeled Values/Achievement Leadership Behaviors.

The fourth factor gathered around reported leadership behaviors and attributes that reflect "developer" leadership skills, with items such as "considers me as having different needs, abilities, and aspirations from others," "treats me as an individual rather than just as a member of a group," "provides me with assistance in exchange for my efforts," and "makes clear what one can expect to receive when performance goals are achieved. Factor 4 was labeled Developer Leadership Behaviors.

The fifth factor gathered around reported leadership behaviors and attributes that reflect (a) "structure" leadership, with items such as "discusses in specific terms who is responsible for achieving performance targets," "expresses satisfaction when I meet expectations," and "keeps track of all mistakes"; as well as (b) "power" leadership, with items such as "displays a sense of power and confidence." Factor 5 was labeled Power/Structure Leadership Behaviors.

Confirmatory factor analysis was selected to further assess the score validity of the alternative five-factor MLQ-5X model. The two primary assumptions of relationship and sufficient sample size were satisfied. The results of the confirmatory factor analysis of the alternative five-factor MLQ-5X model are shown in Figure 2. The reported chi-square was 3.369, which indicated a good model fit for this data (Brown, 2015). The Root Mean Square Error of Approximation (RMSEA) of .058 also indicated a good fit for this model (Brown, 2015).

\subsection{Reliability}

To assess the reliability of the data, Cronbach's alpha was calculated for each of the new factors and is reported in Table 7. Each of the five new factors reported a high Cronbach's alpha, indicating a high level of score reliability (Morgan et al., 2013). The reported Cronbach's alpha for Factor 5 - Power/Structure Leadership Behaviors, was .69, and all others were above .70 .

Table 7. Reported Cronbach's Alpha for Alternative Model Dependent and Independent Variables

\begin{tabular}{llcc}
\hline New Factor & \multicolumn{1}{c}{ Independent and Dependent Variables } & $\begin{array}{c}\text { No. of } \\
\text { Items }\end{array}$ & $\begin{array}{c}\text { Reported Cronbach's } \\
\text { Alpha }\end{array}$ \\
\hline 1 & Exploratory/Latitude Leadership Behaviors & 6 & .87 \\
2 & Visionary/Reflective/Latitude Leadership Behaviors & 8 & .87 \\
3 & Values/Achievement Leadership Behaviors & 5 & .80 \\
4 & Developer Leadership Behaviors - 6 items & 6 & .79 \\
5 & Power/Structure Leadership Behaviors & 4 & .69 \\
& Total Agility Score & 19 & .96 \\
\hline
\end{tabular}

\subsection{Simultaneous Linear Regression - Alternative Model}

The result of the reliability and validity analysis was a new research model consisting of the five new factors of the MLQ-5X as the independent variables and the Total Agility Score as the dependent variable (see Figure 3). Simultaneous linear regression was conducted ( $n=126$ business units) to investigate the best prediction of organization agility using the five factors determined through exploratory factor analysis. A significant correlation was reported between four of the five factors (see Table 8). 
Independent Variables

Dependent Variable

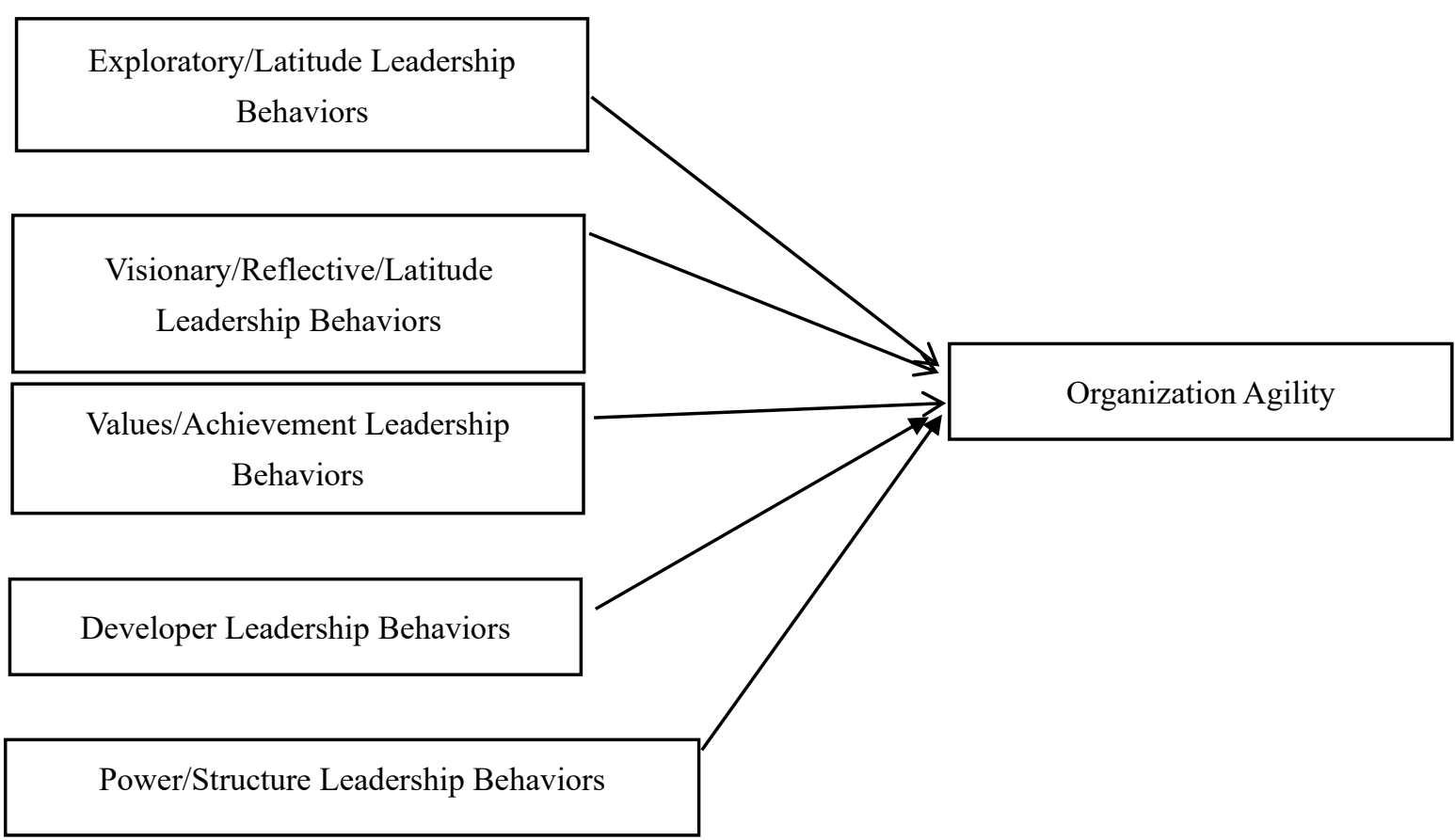

Figure 3. Alternative MLQ-5X Factor Model and Research Design

Table 8. Means, Standard Deviations, and Pearson Correlation for Total Agility Score and MLQ-5X Five-Factor Leadership Behaviors as Predictor Variables

\begin{tabular}{|c|c|c|c|c|c|c|c|}
\hline \multirow[b]{2}{*}{ Variable } & \multirow[b]{2}{*}{$M$} & \multirow[b]{2}{*}{$S D$} & \multicolumn{5}{|c|}{ Leadership Style } \\
\hline & & & $\begin{array}{l}\text { Exploratory/ } \\
\text { Latitude }\end{array}$ & $\begin{array}{c}\text { Visionary/ } \\
\text { Reflective/ } \\
\text { Latitude }\end{array}$ & $\begin{array}{c}\text { Values/ } \\
\text { Achievement }\end{array}$ & Developer & $\begin{array}{l}\text { Power/ } \\
\text { Structure }\end{array}$ \\
\hline Total Agility Score & 3.92 & .43 & $.44 * *$ & $.46^{* *}$ & $-.27 * *$ & $.36^{* *}$ & -.17 \\
\hline $\begin{array}{l}\text { Exploratory/ Latitude Leadership } \\
\text { Behaviors }\end{array}$ & 3.69 & .57 & -- & $.75^{* *}$ & $-.57 * *$ & $.71 * *$ & .09 \\
\hline $\begin{array}{l}\text { Visionary/ Reflective/ Latitude } \\
\text { Leadership Behaviors }\end{array}$ & 4.13 & .51 & & -- & $-.60 * *$ & $.70 * *$ & .01 \\
\hline $\begin{array}{l}\text { Values/ Achievement Leadership } \\
\text { Behaviors }\end{array}$ & 1.56 & .48 & & & -- & $-.62 * *$ & -.02 \\
\hline Developer Leadership Behaviors & 4.16 & .43 & & & & -- & -.13 \\
\hline Power/StructureLeadership Behaviors & 2.59 & .56 & & & & & -- \\
\hline
\end{tabular}

$* p<.05 ; * * p<.01$

The combination of variables to predict the Total Agility Score from Exploratory/Latitude Leadership (Factor 1), Visionary/Reflective/Latitude Leadership (Factor 2), Values/Achievement Leadership (Factor 3), Developer Leadership (Factor 4), and Accountability Leadership (Factor 5) was found to be significant, $F(5,1.3)=9.0, p<.001$. The beta coefficients are presented in Table 10 . The $\mathrm{R}^{2}$ value was .27 , adjusted $\mathrm{R}^{2}$ of .24 , indicating that $24 \%$ of the variance in Total Agility Score was explained by the model. According to Cohen (1988), this was a large or larger-than-typical effect. 
Table 9. Simultaneous Linear Regression Summary for MLQ-5X Five-Factor Leadership Behavior Model Predicting Total Agility Score

\begin{tabular}{|c|c|c|c|c|c|}
\hline Variable & $B$ & $S E B$ & $\beta$ & $t$ & $p$ \\
\hline Exploratory/Latitude Leadership Behaviors & 0.231 & 0.100 & 0.30 & 2.32 & .022 \\
\hline Visionary/Reflective/Latitude Leadership Behaviors & 0.272 & 0.110 & 0.32 & 2.46 & .015 \\
\hline Values/Achievement Leadership Behaviors & 0.040 & 0.095 & 0.04 & 0.42 & .678 \\
\hline Developer Leadership Behaviors & -0.081 & 0.130 & -0.08 & -0.63 & .531 \\
\hline Power/Structure Leadership Behaviors & -0.161 & 0.064 & -0.21 & -2.52 & .013 \\
\hline
\end{tabular}

Note. Adjusted $\mathrm{R}^{2}=.24 ; F(5,120)=9.0, p<.001$

Table 10. Means, Standard Deviations, and Pearson Correlation for Total Agility Score and MLQ-5X Three-Factor Leadership Model

\begin{tabular}{|c|c|c|c|c|c|}
\hline Variable & $M$ & $S D$ & $\begin{array}{l}\text { Exploratory/ } \\
\text { Latitude } \\
\text { Leadership } \\
\text { Behaviors } \\
\end{array}$ & $\begin{array}{l}\text { Visionary/ } \\
\text { Reflective/ } \\
\text { Latitude } \\
\text { Leadership } \\
\text { Behaviors } \\
\end{array}$ & $\begin{array}{l}\text { Power/Structure } \\
\text { Leadership } \\
\text { Behaviors }\end{array}$ \\
\hline Total Agility Score & 3.92 & .43 & $.44 * *$ & $.46^{* *}$ & -.17 \\
\hline Exploratory/Latitude Leadership Behaviors & 3.69 & .57 & -- & $.75 * *$ & .09 \\
\hline Visionary/ Reflective/ Latitude Leadership Behaviors & 4.13 & .51 & & -- & .01 \\
\hline Power/Structure Leadership Behaviors & 2.59 & .56 & & & -- \\
\hline
\end{tabular}

Note. ${ }^{*} p<.05 ;{ }^{* *} p<.01$.

Tolerance and VIF were examined, and no multicollinearity was reported (Tabachnick \& Fidell, 2007). The residual scatterplot indicated that the error, or residual, was normally distributed and uncorrelated with the predictors, satisfying the assumption of independence of observations, or homoscedasticity.

Because Factor 3, Values/Achievement Leadership, was not normal (skewness $=2.25$ ) and potentially did not represent a linear relationship with the dependent variable, Total Agility Score, and because both Factor 3, Values/Achievement Leadership Behaviors, and Factor 4, Developer Leadership Behaviors, reported high correlation, simultaneous linear regression was conducted with these two factors removed from the new model (see Table 11).

Table 11. Simultaneous Linear Regression Summary for MLQ-5X Three-Factor Leadership Behavior Model Predicting Total Agility Score

\begin{tabular}{lccccc}
\hline Variable & $B$ & $S E B$ & $\beta$ & $t$ & $p$ \\
\hline Exploratory/Latitude Leadership Behaviors & .194 & .090 & .255 & 2.17 & .032 \\
Visionary/Reflective/Latitude Leadership Behaviors & .231 & .100 & .270 & 2.31 & .023 \\
Power/Structure Leadership Behaviors & -.149 & .061 & -.191 & -2.44 & .016 \\
\hline
\end{tabular}

Note. Adjusted $\mathrm{R}^{2}=.25 ; F(3,122)=14.9 p<.001$.

The combination of variables to predict the Total Agility Score from Exploratory/Latitude Leadership, Visionary/Reflective/Latitude Leadership, and Power/Structure Leadership was found to be significant, $F(3,122)=$ $14.9, p<.001$. The beta coefficients are presented in Table 15 . The $\mathrm{R}^{2}$ value was .27 , adjusted $\mathrm{R}^{2}$ value of .25 , indicating that $25 \%$ of the variance in Total Agility Score was explained by the model. According to Cohen (1988), this was a large or larger-than-typical effect.

Tolerance and VIF were examined, and no multicollinearity was reported (Tabachnick \& Fidell, 2007). The residual scatterplot indicated that the error, or residual, was normally distributed and uncorrelated with the predictors, satisfying the assumption of independence of observations, or homoscedasticity.

For this model, Factor 1 and 2, the Exploratory/Latitude Leadership Behaviors and Visionary/Reflective/Latitude Leadership Behaviors, were found to predict a higher Total Agility Score; and Factor 5, the Power/Structure Leadership Behaviors, was found to predict a lower Total Agility Score (see Table 12). 


\section{Discussion}

The exploratory factor analysis conducted for this study resulted in a modified five-factor model for the MLQ-5X, and simultaneous linear regression revealed that three of these factors predict higher or lower levels or organization agility as measured by the Total Agility Score of that business unit. Each of the five factors is discussed here in turn.

Factor 1 discussion - exploratory/latitude leadership. Factor 1, labeled Exploratory/Latitude Leadership, seems to reflect two primary elements of leadership behaviors: (a) encouraging employees to look at new ways of completing assignments and solving problems, and (b) avoiding involvement in issues until they become chronic. The data supporting that this factor predicts higher levels of organization agility seems to be supported by research on organization agility (Brown \& Eisenhardt, 1998; Dove, 1999; Holbeche, 2015; Meyer, 2015; Nagel, 1992; Worley et al., 2014).

The first element, looking at new ways of completing assignments and solving problems, was one of the core elements of several conceptual frameworks of agility in that the culture of the organization must support the engagement and empowerment of employees to explore new ways of doing business (Brown \& Eisenhardt, 1998; Goldman et al., 1995; Holbeche, 2015; Meyer, 2015; Worley et al., 2014). The proponents of values-based leadership describe successful leaders as those who listen to the "wild ideas" of others and encourage opinions (O'Toole, 1996). These leaders create a culture that reduces the risk of sharing new, seemingly wild ideas and encourages new perspectives (Crocitto \& Youssef, 2003; Kotter, 2012; Meyer, 2015). Specific attention is given to the development of devil's advocates that stimulate alternative views and a willingness to take risks (Sull, 2009).

The second element of leadership behaviors reflected in this factor, involving the lack of leader engagement in problems before they become chronic, was less obvious when comparing this element to the research on organization agility (Holbeche, 2015; Meyer, 2015; Nagel, 1992; Worley et al., 2014). However, researchers of organization agility do describe the leaders of agile organization as having a hand-off approach in which employees have the latitude to complete their work within the guidelines of the overarching mission and purpose of the organization (Worley et al., 2014). Leadership derived from military strategy, a command-and-control style that involves a tight hold on the reins of the organization, does not foster organization agility (Meyer, 2015; Northouse; 2013; O'Toole, 1996). There needs to be a dynamic stability between the potential chaos of a complete lack of organization structure and the restrictive nature of a command-and-control leadership style (Crocitto \& Youssef, 2003). The leaders of agile organizations often take a hand-off approach, empowering those who work for them to take responsibility and lead (Brown \& Eisenhardt, 1998; Kotter, 2012). This includes identifying elements of the organization that do not support empowerment, including systemic issues such as hierarchical operating systems (Kotter, 2012, 2014).

In summary, research related to organization agility seems to support that Factor 1, Exploratory/Latitude Leadership, predicts higher levels of organization agility (Dove, 1999; Brown \& Eisenhardt, 1998; Holbeche, 2015; Meyer, 2015; Nagel, 1992; Worley et al., 2014). Leaders who exhibit behaviors that encourage exploring new ways of conducting business and lead in a manner that provides latitude and empowerment for their team members to lead, make decisions, and resolve issues on their own, promote an organization culture that fosters higher levels of organization agility (Holbeche, 2015; Goldman et al., 1995; Nagel, 1992; Worley et al., 2014).

Factor 2 discussion - visionary/reflective/latitude leadership. Factor 2, labeled Visionary/Reflective/Latitude Leadership, seems to include three elements of leadership behaviors that predict higher levels of organization agility: (a) the elements related to setting a clear purpose and a positive future vision of the organization, (b) the reflective element of re-examining critical assumptions and seeking different perspectives, and (c) the similar hand-off element of Factor 1 - Exploratory/Latitude Leadership.

The first element, behaviors related to defining the purpose of the organization, was supported by research on organization agility as being important to achieving higher levels of organization agility (Holbeche, 2015; Nahmias \& Perkins, 2012; Worley et al., 2015). By defining a compelling sense of purpose for the organization, the leader is creating the foundation that supports the agile-related routines of strategizing and implementing (Worley et al., 2014). This includes the creation of a common identity made up of the vision, values, and culture of the organization, all aligned to support agility (O'Reilly \& Tushman, 2016). By declaring a purpose, employees understand the "why we exist," giving them the latitude to be exploratory in the "how we accomplish this" (Nahmias \& Perkins, 2012). Organizational purpose lays the foundation for employees to generate creative solutions to emerging problems (Schein, 2010).

The reflective element - while similar to the exploratory element in Factor 1 related to exploring new ways of doing things - was more reflective in nature in that it relates to re-examining critical assumptions considering today's 
business environment, a core leadership capability in agile organizations (Crocitto \& Youssef, 2003; Joiner \& Josephs, 2007; Nahmias \& Perkins, 2012; Worley et al., 2014). Worley et al. (2014) stated:

We know from psychology that there is a bias to dismiss such data even though they may be right. TMT's must possess the methods and group dynamics to challenge their own assumptions, or have a process in place for having others, such as a board of directors, who can challenge assumptions. Either way, having a culture in which the status quo can be challenged is important. (p. 78)

Leaders of agile organizations encourage others to challenge automatic thoughts (Goldman et al., 1995; Meyer, 2015). Employees are encouraged to take responsibility for their own learning, to seek new perspectives, and to challenge assumptions and experiences (Nahmias \& Perkins, 2012). This includes the art of actively noticing issues and problems that arise, trying on new perspectives, and creatively thinking on one's feet (Meyer, 2015; Nagel, 1992). Employees must have the freedom and voice to challenge the status quo (Beer, 2009; Holbeche, 2015). The final element, latitude, was reflected in this factor as described above in the Factor 1 discussion.

In summary, research related to organization agility seems to support that Factor 2, Visionary/Reflective/Latitude Leadership, predicts higher levels of organization agility (Goldman et al., 1995; Holbeche, 2015; Nagel, 1992; Worley et al., 2014). Leaders who exhibit behaviors that create a strong sense of purpose for the organization, encourage employees to challenge assumptions and explore new perspectives, and empower them to lead and resolve issues, are supporting the development of higher levels of organization agility (Goldman et al., 1995; Holbeche, 2015; Nagel, 1992; Worley et al., 2014).

Factor 3 discussion - values/achievement leadership. While this factor did not predict higher or lower levels of organization agility it is worth reflecting on briefly. This factor seems to reflect two elements of leadership behavior: (a) behaving in a way that is values-based and moral, and (b) focusing upon the achievement of organizational goals. Several theories of leadership researched for this study discuss ethics and values as a component of that leadership style, indicating that a factor reflecting values behavior may not be a differentiating point for leadership behaviors and attributes (Bass \& Riggio, 2006; Greenleaf, 1977; Lynham \& Chermack, 2006; Northouse, 2013; O’Toole, 1996).

Factor 4 discussion - developer leadership. This factor reflected elements of leadership behavior related to a leader as someone who develops those who work for them by considering them as individuals with unique needs, making clear what will be received when achieving performance goals, and providing employees with assistance. This factor did not predict higher or lower levels of organization agility, which was consistent with the limited discussion of these types of behaviors in the organization agility literature reviewed (Goldman et al., 1995; Holbeche, 2015; Nagel, 1992; Worley et al., 2014). The leaders of agile organizations exhibit behaviors that are focused more upon empowering people as leaders who take on responsibility for their own development and are responsible leaders (Meyer, 2015; O'Toole, 1996). This would support that this factor does not predict higher or lower levels of organization agility in this study (Holbeche, 2015; Goldman et al., 1995; Nagel, 1992; O’Toole, 1996; Worley et al., 2014).

Factor 5 discussion - power/structure leadership. This factor appears to reflect the elements of leadership behavior related to setting and achieving goals and putting structure in place, including defining who within the organization is responsible for what tasks, expressing satisfaction when goals are met, and keeping track of mistakes, as well as leaders exuding power and confidence. This factor was found to predict lower levels of organization agility for the business units studied. Research indicates that an important leadership element of organization agility is promoting a culture in which mistakes are treated as learning opportunities versus treating them as failures, as is implied by this factor (Goldman et al., 1995; Holbeche, 2015; Schein, 2010; Worley et al., 2015). The element of assigning tasks of this factor appears similar to a more structured, bureaucratic style of leadership that does not support the flexibility of structure and rapidly reconfigurable resources necessary for an organization to have high levels of agility (Worley et al., 2014).

In summary, the research reviewed related to organization agility supports that this factor predicts a lower level of agility of the organization (Goldman et al., 1995; Holbeche, 2015; Meyer, 2014; Nagel, 1992; Worley et al., 2015). Agile organizations encourage new ideas without fear of mistakes and a fluid organization structure that supports the need for constant change in reaction to changes in the business environment (Goldman et al., 1995; Meyer, 2015; Worley et al., 2014). 


\section{Limitations of the Research}

By selecting organizations with greater than 1,000 employees as the target population, the research results may not be generalizable to smaller organizations (Gliner et al., 2009). Selecting only U.S.-based business units also limits the generalizability of the results to non-U.S.-based business units, and the study did not consider the cultural implications of U.S.-based business units within non-U.S. corporations (Gliner et al., 2009). The variety of industries and types of organizations contained in the sample could be viewed as either enhancing or detracting from the generalizability of the findings (Swanson \& Holton, 2005).

Each organization was responsible for the random selection of the 20 employees chosen to receive the Agility Survey (short-form), and although clear instructions were provided on what was or was not considered a random sampling method, the sampling methodology of these employees was not controlled (Swanson \& Holton, 2005). For the Total Agility Score, a response of at least three employees was considered to be adequate, with an average number of respondents per business unit of 13.9 (Worley et al., 2014). For the MLQ-5X, prior research had indicated a minimum of three direct report respondents per leader (Avolio \& Bass, 2004). For this study, 12 of the 126 participating business unit leaders had only one or two direct reports, eliminating the ability to collect data from three direct reports. Demographic information was not collected related to the tenure of the business unit leader in that position or the numbers of years each respondent had reported to that business unit leader, which is a limitation to the study in that leaders and followers with a short tenure in the position and/or relation may not have indicated accurate data.

The decision to utilize the MLQ-5X to measure leadership behaviors and attributes was based upon extensive use of the instrument and the reliability scores reported in prior research (Bass \& Riggio, 2006; Franco \& Matos, 2013; Gencer \& Samur, 2016; Luo et al., 2016; Popli \& Rizvi, 2016). Because the data for this study did not factor according to the assumed factor structure, one could challenge the validity of the instrument in this instance (Gliner et al., 2009; Swanson \& Holton, 2005). The Cronbach's alpha scores and strong pattern matrix indicate that the factor structure reported for this study was acceptable (Morgan et al., 2013). The MLQ-5X also does not include items related to some leadership behaviors and attributes reflected in the conceptual frameworks of organization agility (Brown \& Eisenhardt, 1998; Goldman et al., 1995; Holbeche, 2015; Meyer, 2015; Worley et al., 2014). These include leadership behaviors related to scanning the business environment and providing resources to test new products and services (Worley et al., 2014).

\subsection{Implications for Leadership Theory, Research, and Practice}

Leadership theorists have put forth many conceptualizations of modern leadership theory, including shared, transformational, values-based, servant, and responsible leadership (Bass \& Riggio, 2006; Greenleaf, 1977; Lynham \& Chermack, 2006; O'Toole, 1996). This research study contributes to the conceptualization of the theory of leadership by building upon existing conceptual models of organization agility and the elements of leadership contained within these models, and by providing an alternative, five-factor model of leadership with the described elements present (Bass \& Riggio, 2004; Holbeche, 2015; Meyer, 2015; Swanson \& Chermack, 2013). An opportunity exists to further refine the proposed model of leadership factors via future research that will continue the process of theory building related to leadership (Bass \& Riggio, 2004).

Leadership behaviors are critical to the achievement of organization agility (Brown \& Eisenhardt, 1998; Holbeche, 2015; Meyer, 2015; Worley et al., 2014). Practitioners working with organizations to assist them in achieving organization agility are now armed with additional information as to the leadership behaviors and attributes necessary to develop high levels of organization agility. Specifically, practitioners working with leaders to achieve the behaviors related to organization agility should focus upon assessing and building skills and behaviors that are related to (a) exploratory efforts that encourage employees to think about doing business in new ways, (b) latitude behaviors that empower employees and give them the freedom to make decisions and resolve issues, (c) visionary efforts to optimistically define a future state of the organization that is grounded in a clear organization purpose and (d) reflective behaviors that encourage all team members to challenge assumptions and the status quo (Holbeche, 2015; Meyer, 2015; Worley et al., 2015). Practitioners working with leaders who are interested in building highly agile organization should discourage leaders from taking an entirely goal-focused approach to leadership, which creates overly prescriptive structures and processes that constrict innovation and new ways of thinking and encourage leadership behaviors that reduce fear of risk-taking and retribution for mistakes made (Holbeche, 2015; Meyer, 2015; Worley et al., 2015). 


\subsection{Implications for Organization Agility Theory, Research, and Practice}

Organization agility is an immature topic. Several conceptual frameworks for organization agility exist, with limited empirical research to support the existence of these conceptual frameworks within organizations, and the elements and constructs of organization agility are just now being defined by researchers (Holbeche, 2015; Meyer, 2015; Nagel, 1992; Worley et al., 2014). The Agility Survey (short-form) is one attempt to operationalize the theory of organization agility by creating a measurement instrument to assess the presence of four elements, the four routines of strategizing, perceiving, testing, and implementing (Swanson \& Chermack, 2013; Worley et al., 2014). This study adds to our understanding of the conceptual framework of organization agility by providing deeper insight into the behaviors and attributes of the leaders of highly agile business units and organizations via statistical analysis. While those researching organization agility realize the importance of leadership as a core organization capability, the research related to which leadership behaviors and attributes are correlated to high levels of organization agility are limited (Holbeche, 2015; Meyer, 2015; Worley et al., 2014). There is an opportunity to more fully develop the understanding of how leadership behaviors impact organization agility.

The practice of building organizations with high levels of organization agility also benefits from the broad discussion of organization agility reflected in this research, including how it is measured and developed. The score reliability and validity reflected in this research contributes to the confirmation of the existence of organization agility as a phenomenon (Gliner et al., 2009). Working with organizations to develop the four agile routines - agile strategizing, agile perceiving, agile testing, and agile implementation - should result in higher levels of agility for that organization (Worley et al., 2014). This includes efforts to create broadly understood strategies that (a) differentiate the organization from competitors, (b) put in place consistent processes such as scenario planning to perceive changes in the business environment, (c) dedicate resources to testing new ways of doing business, and (d) develop a deep capability for implementing new strategies including the development of new skills (Holbeche, 2015; Meyer, 2015; Worley et al., 2014).

\section{Conclusion}

This research study contributes to the body of knowledge of organization agility by studying which leadership behaviors predict higher or lower levels of organization agility in U.S.-based business units of organizations with greater than 1,000 employees. Based upon a broad assumption that organization agility is a desired capability for an organization, one might apply these learnings to influence the selection, training and development, and retention of leaders who exhibit the behaviors and attributes that predict higher levels of organization agility (Dove, 1999; Holbeche, 2015; Worley et al., 2014).

The leadership elements found to predict higher levels of organization agility include: (a) exploratory leadership behaviors that support discovering new ways to solve problems and conduct business, (b) latitude leadership behaviors that provide employees with a high degree of freedom and responsibility in achieving work results and resolving issues, (c) visionary leadership behaviors that create a clear organization purpose and mission and define the "why" of the organization's existence, and (d) reflective leadership behaviors that cause leaders to challenge their own assumptions and create mechanisms for the organization to do so as well (see Table 13). The leadership behaviors that predict lower levels of organization agility include leadership behaviors related to structure and power.

The organization agility research reviewed for this study supports that these elements of leadership behaviors predict higher levels of organization agility (Brown \& Eisenhardt, 1998; Holbeche, 2015; Meyer, 2015; Worley et al., 2014). The organization agility research reviewed for this study also supports that the leadership elements of power and structure, including the leadership behaviors of clearly assigning tasks and keeping track of mistakes, predict lower levels of organization agility (Brown \& Eisenhardt, 1998; Holbeche, 2015; Meyer, 2015; Worley et al., 2014). By defining the leadership behavior elements captured in Table 16 and describing how these leadership behavior elements predict higher and lower levels or organization agility, theorists, practitioners, and the leaders of organizations may gain greater insight into the leadership behaviors that should be cultivated in leaders to achieve higher levels of organization agility. This will in turn lead to higher levels of organization agility, a critical organization capability that is crucial to the long-term success of an organization (Dove, 1999; Goldman et al., 1995; Holbeche, 2015; Worley et al., 2014). 
Table 12. Leadership Behavior Categories That Predict Higher or Lower Levels of Organization Agility

\begin{tabular}{|c|c|c|}
\hline $\begin{array}{l}\text { Leadership } \\
\text { Behavior } \\
\text { Category }\end{array}$ & Description of Leadership Behaviors & $\begin{array}{l}\text { Prediction of } \\
\text { Organization Agility }\end{array}$ \\
\hline Exploratory & $\begin{array}{l}\text { Leadership behaviors that support a culture of discovering new ways } \\
\text { to solve problems and conduct business; and encourage "crazy } \\
\text { ideas" }\end{array}$ & Predicts higher organization agility \\
\hline Latitude & $\begin{array}{l}\text { Leadership behaviors that provide employees with a high degree of } \\
\text { freedom and responsibility in achieving work results and resolving } \\
\text { issues }\end{array}$ & Predicts higher organization agility \\
\hline Visionary & $\begin{array}{l}\text { Leadership behaviors that create a clear organization purpose and } \\
\text { mission; and define the "why" of the organization's existence }\end{array}$ & Predicts higher organization agility \\
\hline Reflective & $\begin{array}{l}\text { Leadership behaviors that cause leaders and their followers to } \\
\text { challenge existing assumptions and seek new perspectives }\end{array}$ & Predicts higher organization agility \\
\hline Power & $\begin{array}{l}\text { Leadership behaviors that reflect a leader exuding power and } \\
\text { confidence }\end{array}$ & Predicts lower organization agility \\
\hline Structure & $\begin{array}{l}\text { Leadership behaviors that involve creating structured organizations } \\
\text { with clearly defined responsibilities and goals; and keeping track of } \\
\text { mistakes }\end{array}$ & Predicts lower organization agility \\
\hline
\end{tabular}

\section{References}

Avolio, B. J., \& Bass, B. M. (2004). Multifactor leadership questionnaire: Manual and sample set (3rd ed.). Menlo Park, CA: Mindgarden.

Bartlett, J. E., Kotrlik, J. W., \& Higgins, C. C. (2001). Organizational research: Determining appropriate sample size in survey research. Information Technology, Learning, and Performance Journal, 19(1), 43-50.

Bass, B. M. (1991). From transactional to transformational leadership: Learning to share the vision. Organizational Dynamics, 18(3), 19-31. https://doi.org/10.1016/0090-2616(90)90061-S

Bass, B. M. (1995). Theory of transformational leadership redux. Leadership Quarterly, 6, 463-478. https://doi.org/10.1016/1048-9843(95)90021-7

Bass, B. M. (1999). Two decades of research and development in transformational leadership. European Journal of Work and Organizational Psychology, 8(1), 9-32. https://doi.org/10.1080/135943299398410

Bass, B. M., \& Avolio, B. J. (1994). Shatter the glass ceiling: Women may make better managers. Human Resource Management, 33, 549-560. https://doi.org/10.1002/hrm.3930330405

Bass, B. M., \& Riggio, R. E. (2006). Transformational leadership (2nd ed.). New York, NY: Psychology Press.

Beer, M. (2009). High commitment, high performance: How to build a resilient organization for sustained advantage. San Francisco, CA: Jossey-Bass.

Belasco, J. A. (1990). Teaching the elephant to dance: Empowering change in your organization. New York, NY: Crown.

Brown, S., \& Eisenhardt, K. (1998). Competing on the edge: Strategy as structured chaos. Boston, MA: President and Fellows of Harvard College.

Brown, T. A. (2015). Confirmatory factor analysis for applied research (2nd ed.). New York, NY: Guilford Press.

Burke, W. W., \& Litwin G. H. (1992). A Causal model of organizational performance and change. Journal of Management, 18, 523-545. https://doi.org/10.1177/014920639201800306 
Burns, J. M. (1978). Leadership. New York: HarperCollins.

Chermack, T. J. (2001). Scenario planning in organizations: How to create, use, and assess scenarios. Oakland, CA: Berrett-Koehler.

Chermack, T. J., Lynham, S. A., \& Ruona, W. E. A. (2001, Summer). A review of scenario planning literature. Futures Research Quarterly, 7-31.

Cohen, J. (1988). Statistical power and analysis for the behavioral sciences (2nd ed.). Hillsdale, NJ: Lawrence Erlbaum Associates.

Crocitto, M., \& Youssef, M. (2003). The human side of organization agility. Industrial Management \& Data Systems, 103, 388-397. https://doi.org/10.1108/02635570310479963

Dove, R. (1999). Knowledge management, response ability, and the agile enterprise. Journal of Knowledge Management, 3(1), 18-35. https://doi.org/10.1108/13673279910259367

Dubin, R. (1978). Theory building (2nd ed.). New York, NY: Free Press.

Flanigan, R. L., Bishop, J. L., Brachle, B. J., \& Winn, B. A. (2017). Leadership and small firm performance: The moderating effects of demographic characteristics. Creighton Journal of Interdisciplinary Leadership, 3(1), 2-19. http://dx.doi.org/10.17062/CJIL.v3i1.54

Franco, M., \& Matos, P. G. (2013). Leadership styles in SMEs: A mixed method approach. International Entrepreneurship and Management Journal. http://dx.doi.org/10.1007/s11365-013-0283-2

Frieder, R. E., Wang, G., \& Oh, I.-S. (2018). Linking job-relevant personality traits, transformational leadership, and job performance via perceived meaningfulness at work: A moderated mediation model. Journal of Applied Psychology, 103, 324-333. http://dx.doi.org/10.1037/apl0000274

Gencer, M. S., \& Samur, Y. (2016). Leadership styles and technology: Leadership competency levels of educational leaders. Fifth International Conference on Leadership, Technology, Innovation and Business Management. Procedia - Social and Behavioral Sciences, 229, 226-233. http://dx.doi.org/10.1016/j.sbspro.2016.07.132

Gliner, J. A., Morgan, G. A., \& Leech, N. L. (2009). Research methods in applied settings: An integrated approach to design and analysis (2nd ed.). New York, NY: Routledge.

Goldman, S. L., Nagel, R. N., \& Preiss, K. (1995). Agile competitors and virtual organizations: Strategies for enriching the customer. New York, NY: International Thompson.

Greenleaf, R. K. (1977). Servant leadership: A journey into the nature of legitimate power and greatness. New York, NY: Paulist Press.

Hemsworth, D., Muterera, J., \& Baregheh, A. (2013). Examining Bass's transformational leadership in public sector executives: A psychometric properties review. The Journal of Applied Business Research, 28, 131-144. https://doi.org/10.19030/jabr.v29i3.7785

Holbeche, L. (2015). The agile organization: How to build an innovative, sustainable and resilient business. London, UK: Kogan Page.

Iivari, J., \& Iivari, N. (2010). The relationship between organizational culture and the deployment of agile methods. Information and Software Technology, 53, 509-520. https://doi.org/10.1016/j.infsof.2010.10.008

Joiner, B., \& Josephs, S. (2007). Leadership agility: Five levels of mastery for anticipating and initiating change. San Francisco, CA: Jossey-Bass.

Kotter, J. P. (2012). Leading change (2nd ed.). Boston, MA: Harvard Business Review Press.

Kotter, J. P. (2014). Accelerate: Building strategic agility for a faster-moving world. Boston, MA: Harvard Business Review Press.

Leech, N. L., Barrett, K. C., \& Morgan, G. A. (2015). IBM SPSS for intermediate statistics: Use and interpretation (5th ed.). New York, NY: Routledge.

Luo, Z., Wang, Y., Marnburg, E., \& Ogaard, T. (2016). How is leadership related to employee self-concept? International Journal of Hospitality Management, 51, 24-32. https://doi.org/10.1016/j.ijhm.2015.09.003

Lynham, S. A. (2002). Quantitative research and theory building: Dubin's model. Advances in Developing Human Resources, 4, 242-276. https://doi.org/10.1177/15222302004003003 
Lynham, S. A., \& Chermack, T. J. (2006). Responsible leadership for performance: A theoretical model and hypothesis. Journal of Leadership and Organizational Studies, 12(4), 73-88. https://doi.org/10.1177/107179190601200405

Meyer, P. (2015). The agility shift: Creating agile and effective leaders, teams and organizations. Brookline, MA: Bibliomotion.

Morgan, G. (2006). Images of organization. Thousand Oaks, CA: SAGE.

Morgan, G. A., Leech, N. L., Gloeckner, G. W., \& Barrett, K. C. (2013). IBM SPSS for introductory statistics (5th ed.). New York, NY: Routledge.

Nagel, R. N. (1992). $21^{\text {st }}$ century manufacturing: Enterprise strategy report. (Report No. AD-A257 032). Arlington, VA: Office of Naval Research.

Nahmias, A. H., \& Perkins, A. (2012). The agile change methodology: A researched organizational change maturity model helping organizations become agile, a proven change management method. Saarbrucken, Germany: Lambert Academic.

Northouse, P. G. (2013). Leadership: Theory and practice (6th ed.). Thousand Oaks, CA: SAGE.

O’Reilly, C. A., III, \& Tushman, M. L. (2016). Lead and disrupt: How to solve the innovator's dilemma. Stanford, CA: Stanford University Press.

O’Toole, J. O. (1996). Leading change: The argument for values-based leadership. New York, NY: Ballentine.

Popli, S., \& Rizvi, I. A. (2016). Drivers of employee engagement: The role of leadership style. Global Business Review, 17, 965-979. https://doi.org/10.1177/0972150916645701

Schein, E. H. (2010). Organizational culture and leadership. San Francisco, CA: Jossey-Bass.

Sharifi, H., \& Zhang, Z. (1999). A methodology for achieving agility in manufacturing organisations: An introduction. International Journal of Production Economics, 62, 7-22. https://doi.org/10.1016/S0925-5273(98)00217-5

Sharifi, H., \& Zhang, Z. (2001). Agile manufacturing in practice: Application of methodology. International Journal of Operations and Production Management, 21, 772-794. https://doi.org/10.1108/01443570110390462

Sull, D. (2009). The upside of turbulence: Seizing opportunity in an uncertain world. New York, NY: HarperCollins.

Swanson, R. A., \& Chermack, T. J. (2013). Theory building in applied disciplines. San Francisco, CA: Berrett-Koehler.

Swanson, R. A., \& Holton, E. F., III. (2005). Research in organizations: Foundations and methods in inquiry. Oakland, CA: Berrett-Koehler.

Tabachnick, B. G., \& Fidell, L. S. (2007). Using multivariate statistics (5th ed.). Boston, MA: Pearson Education.

Tushman, M. L., \& O'Reilly, C. A., III. (1996). Ambidextrous organizations: Managing evolutionary and revolutionary change. California Management Review, 38(4), 8-30. https://doi.org/10.2307/41165852

Williams, D. E. (2008). Developing libraries as nimble organizations. Technical Services Quarterly, 18(4), 35-46. https://doi.org/10.1300/J124v18n04_04

Worley, C. G., \& Lawler E. E. (2009). Agility and the organization design: A diagnostic framework. Center for Effective Organizations, 1-37. https://doi.org/10.1016/j.orgdyn.2010.01.006

Worley, C. G., Williams, T., \& Lawler, E. E, III. (2014). The agility factor: Building adaptable organizations for superior performance. San Francisco, CA: Jossey-Bass.

Zhang, Z., \& Sharifi, H. (2007). Towards theory building in agile manufacturing strategy: A taxonomical approach. IEEE Transactions on Engineer Management, 54, 351-370. https://doi.org/10.1109/TEM.2007.893989

\section{Copyrights}

Copyright for this article is retained by the author(s), with first publication rights granted to the journal.

This is an open-access article distributed under the terms and conditions of the Creative Commons Attribution license (http://creativecommons.org/licenses/by/4.0/). 